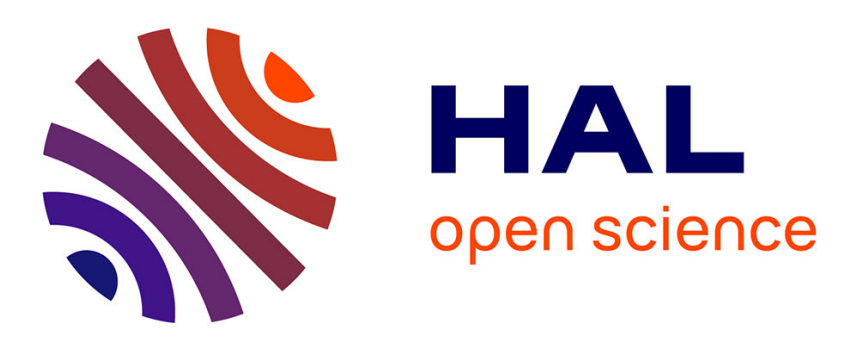

\title{
Anaerobic Removal of Trace Organic Contaminants in Sewage Sludge: 15 Years of Experience
}

Maialen Barret, Liliana Delgadillo-Mirquez, Eric Trably, Nadine Delgenes, Florence Braun, Glenda Cea-Barcia, Jean-Philippe Steyer, Dominique

Patureau

\section{To cite this version:}

Maialen Barret, Liliana Delgadillo-Mirquez, Eric Trably, Nadine Delgenes, Florence Braun, et al.. Anaerobic Removal of Trace Organic Contaminants in Sewage Sludge: 15 Years of Experience. Pedosphere, 2012, vol. 22 (4), pp. 508-517. 10.1016/s1002-0160(12)60035-6 . hal-01015845

\section{HAL Id: hal-01015845 \\ https://hal.science/hal-01015845}

Submitted on 27 Jun 2014

HAL is a multi-disciplinary open access archive for the deposit and dissemination of scientific research documents, whether they are published or not. The documents may come from teaching and research institutions in France or abroad, or from public or private research centers.
L'archive ouverte pluridisciplinaire HAL, est destinée au dépôt et à la diffusion de documents scientifiques de niveau recherche, publiés ou non, émanant des établissements d'enseignement et de recherche français ou étrangers, des laboratoires publics ou privés. 


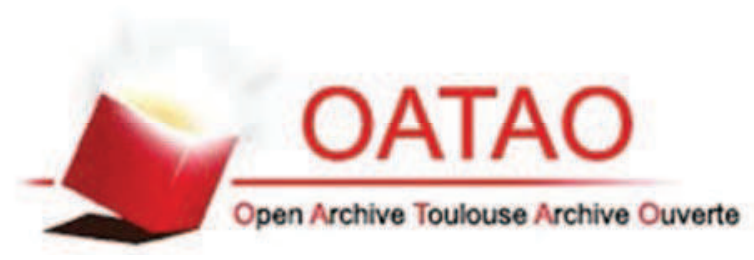

\section{Open Archive TOULOUSE Archive Ouverte (OATAO)}

OATAO is an open access repository that collects the work of Toulouse researchers and makes it freely available over the web where possible.

This is an author-deposited version published in : http://oatao.univ-toulouse.fr/ Eprints ID : 11770

To link to this article : DOI: 10.1016/S1002-0160(12)60035-6 URL : http://www.sciencedirect.com/science/article/pii/S1002016012600356\#

To cite this version : Barret, Maialen and Delgadillo-Mirquez, Liliana and Trably, Eric and Delgenès, Nadine and Braun, Florence and Cea-Barcia, Glenda and Steyer, Jean-Philippe and Patureau, Dominique Anaerobic Removal of Trace Organic Contaminants in Sewage Sludge: 15 Years of Experience. (2012) Pedosphere, vol. 22 $\left(\mathrm{n}^{\circ} 4\right)$. pp. 508-517. ISSN 1002-0160

Any correspondance concerning this service should be sent to the repository administrator: staff-oatao@,listes-diff.inp-toulouse.fr 


\title{
Anaerobic Removal of Trace Organic Contaminants in Sewage Sludge: 15 Years of Experience*1
}

\author{
M. BARRET, L. DELGADILlO-MIRQUEZ, E. TRABLy, N. DELGENES, F. BRAUN, G. CEA-BARCiA, \\ J. P. STEYER and D. PATUREAU*2 \\ INRA, UR0050, Laboratoire de Biotechnologie de l'Environnement, Narbonne F-11100 (France)
}

\begin{abstract}
Trace organic contaminants (TOCs) correspond to a broad range of molecules generated either directly or indirectly by human activity. Even though TOCs are found at low concentrations in the environment, they often accumulate by biomagnification and bioaccumulation into biological organisms and cause irreversible damages in biological systems through direct or indirect toxic effects such as endocrine disruption and tumour initiation. This manuscript presents the main findings of over fifteen years of research focusing on biological removal of various TOCs found in sewage sludge from urban treatment plants. A special focus of the research was made on microbial processes in complex anaerobic ecosystems. Four families of compounds mostly retrieved in urban plants were studied: the polycyclic aromatic hydrocarbons (PAHs), the polychlorobiphenyls (PCBs), the phthalic acid esters (PAEs), and the nonylphenol ethoxylates (NPEs). It was observed that the microbial capability for removing low amounts of TOCs required a long adaptation time and was often limited by the bioavailability of these compounds. In fact, the overall biodegradation resulted from the numerous interactions existing between the matrix (organic matter) and the microbial ecosystems according to the physico-chemical sorption properties of these compounds. Mechanistic aspects were also tackled in depth and specific models were developed for better understanding the network of interactions between TOCs, microorganisms, and organic matter. These findings could be extrapolated to other ecosystems such as soils and sediments. Finally, it was shown that microbial cometabolism was essential for TOC removal, and the concept of bioavailability was not only dependent on the nature, the level, and the sorption properties of TOCs but was also strongly dependent on the nature and the concentration of the sludge organic matter. Specific parameters were proposed for better evaluating the fate of TOCs in microbial anaerobic processes and technological solutions for efficient removal of these compounds were also proposed.

Key Words: $\quad$ anaerobic digestion, bioavailability, biodegradation, microbial cometabolism, organic matter
\end{abstract}

Citation: Barret, M., Delgadillo-Mirquez, L., Trably, E., Delgenes, N., Braun, F., Cea-Barcia, G., Steyer, J. P. and Patureau, D. 2012. Anaerobic removal of trace organic contaminants in sewage sludge: 15 years of experience. Pedosphere. 22(4): $508-517$.

\section{INTRODUCTION}

A broad range of natural and man-made trace organic contaminants (TOCs) enter the environment through sewage treatment plants (STPs). During the last two decades, many research projects have focused on i) the improvement of analytical methods for the determination of TOCs and their by-product metabolites in wastewaters and sludge, i.e., in complex media (Celiz et al., 2009); ii) the presence of these TOCs in raw sewage, treated water, and various environmental matrices (Jensen, 1999; Bolz et al., 2001; Monteiro and Boxall, 2010); iii) the assessment and prediction of their harmful effects on ecosystems (Jobling and Sumpter, 1993; Desbrow et al., 1998; Servos, 1999) and the data acquisition for environmental and human risk assessment (Wild and Jones, 1992; Darbre, 1998; Mackay and Fraser, 2000; Martin and Voulvoulis, 2009); and iv) the evaluation of conventional wastewater and upgraded processes to remove some priority and emerging TOCs (Muller et al., 2008; Gabet-Giraud et al., 2010).

Since biological processes are extensively used in urban wastewater treatment plants, many studies have focused on the efficiency of biological treatments and the influence of the operating parameters associated with these systems (e.g., solids retention time, hydraulic retention time, and fixed or suspended biomass) (Clara et al., 2005). As it was demonstrated that removal of TOCs was related to their biodegrada- 
bility (Joss et al., 2006), sorption is one of the main mechanisms that drive their fate in STPs, particularly for hydrophobic TOCs (Fauser et al., 2003; Gadd, 2009). The results of the French National Amperes Project (2005-2008) fully support these assumptions. It was demonstrated that among the substances removed from water by conventional activated sludge (with an average removal efficiency > 30\%), 65\% of TOCs are transferred from the liquid to the solid phase of the mixed liquor.

Simultaneously to the studies in STPs, many investigations have focussed on TOC occurrence in sewage sludge, particularly on the analytical development from such complex organic matrices (Magoarou, 2000). A broad variation of the levels found in the literature is due to the diverse analytical methodologies and the variability of the wastewater and sludge treatment processes. However, it seems that some TOCs, e.g., detergents and plasticizers, are characterized by very high levels of contamination, from $\mathrm{g}$ to $\mathrm{mg} \mathrm{kg}^{-1}$ dry matter (DM), and some others such as hydrocarbons, pesticides, flame retardants, and pharmaceuticals by low (100-1000 $\left.\mathrm{gg} \mathrm{kg}^{-1} \mathrm{DM}\right)$ to very low (< $\left.100 \mu \mathrm{g} \mathrm{kg}{ }^{-1} \mathrm{DM}\right)$ levels of contamination.

As a consequence, several countries have already implemented cut-off values for these contaminants found in sewage sludge, and the European Union (EU) proposed in 2000 a draft for modifying the Sewage Sludge Directive of 1986 . In this draft, limit values of TOC concentrations in sludge and annual amounts prior to reuse in agriculture were proposed: $2600 \mathrm{mg}$ $\mathrm{kg}^{-1} \mathrm{DM}$ for linear alkylbenzene sulfonates, $100 \mathrm{mg}$ $\mathrm{kg}^{-1} \mathrm{DM}$ for diethylhexylphthalates, $50 \mathrm{mg} \mathrm{kg}^{-1} \mathrm{DM}$ for nonylphenol polyethoxylates (NPEs), $100 \mathrm{ng}$ toxic equivalent quantity (TEQ) $\mathrm{kg}^{-1} \mathrm{DM}$ for dioxins and furans, $500 \mathrm{mg} \mathrm{kg}^{-1} \mathrm{DM}$ for organohalogens, 0.8 $\mathrm{mg} \mathrm{kg}{ }^{-1} \mathrm{DM}$ for polychlorobiphenyls (PCBs), and 6 $\mathrm{mg} \mathrm{kg}^{-1} \mathrm{DM}$ for polycyclic aromatic hydrocarbons (PAHs). Some European countries have already applied such limits: Germany since 1992, Denmark since 1997, and France since 1998 (Magoarou, 2000).

For sludge stabilisation, biological processes have been considered as standard treatment methods in the EU for several decades. While liquid aerobic stabilisation is normally preferred in small wastewater treatment plants, medium or large treatment plants normally use anaerobic stabilization, also called sludge digestion. This latter process is known to be more attractive with respect to energy considerations. It requires less energy than aerobic treatments and produces a renewable and storable energy source in the form of bio- gas. Nonetheless, aerobic treatments and their associated microbial populations and metabolic pathways of TOC removal have been largely studied and well applied at real scale (waste and wastewater treatment and bioremediation technologies). One of the most studied anaerobic metabolic pathways is the reductive dehalogenation occurring with organohalogenic compounds like perchloroethylenes, PCBs, or hexachlorocyclohexanes (Smidt and de Vos, 2004). Many studies have also dealt with the anaerobic biodegradation of aromatic compounds like benzene, toluene, ethylbenzene, and xylene (Gibson and Harwood, 2002). All these studies were usually conducted on highly contaminated ecosystems such as lake sediments, anthropogenic soils, or industrial wastewaters. However, only little is known about low contaminated environments such as sewage sludge. Fifteen years ago, the knowledge in the field of TOC fate during anaerobic sludge stabilisation was very poor. At this time, it was really challenging to get data on their fate, their removal optimization, the implied microbial population, and the key parameters and mechanisms driving their fate in order to reduce their further impact on soils after sludge spreading. All these research topics are detailed in the present paper with emphasis on the main results obtained from the past 15 years of research. Some TOCs were chosen as model compounds according to their variability in their chemical structures, fate in STP (degradation/sorption/volatilisation), persistence and toxicity in the environment, and existence of cutoff values in EU policies. Four families were thus studied: PAHs, PCBs, phthalic acid esters (PAEs), and NPEs.

\section{MATERIALS AND METHODS}

\section{Biological reactors fed with long-term TOC-contami- nated sewage sludge}

Four (aerobic) or 5-L (anaerobic) continuous stirred tank reactors (CRTR) were used and operated at laboratory scale. Magnetic stirring was used for reactor mixing and $\mathrm{pH}$ was not regulated but maintained around $7.6 \pm 0.1$. Reactors were operated at mesophilic $\left(35^{\circ} \mathrm{C}\right)$, intermediate $\left(45^{\circ} \mathrm{C}\right)$, and thermophilic $\left(55{ }^{\circ} \mathrm{C}\right)$ conditions, and fed with long-term TOC-contaminated sewage sludge (contamination in either PAHs, PCBs, or NPEs). TOC removals were assessed at the steady state, i.e., after 4-5 hydraulic retention times under continuous operation. To assess TOC abiotic losses, a sterilizing chemical (100 mmol $\mathrm{L}^{-1}$ sodium azide) was added to control reactors ope- 
rated under similar conditions to biological ones. Total solids (TS) and volatile solids (VS) were determined by drying $20 \mathrm{~mL}$ of the sludge sample in an oven at 110 ${ }^{\circ} \mathrm{C}$ for $24 \mathrm{~h}$ and at $550{ }^{\circ} \mathrm{C}$ overnight, respectively.

For the anaerobic digesters, the operating conditions were similar to those of the industrial digesters with a hydraulic retention time ranging from 20 to $40 \mathrm{~d}$ and a maximum daily organic load (in terms of chemical oxygen demand (COD)) of $1 \mathrm{~kg} \mathrm{COD} \mathrm{m} \mathrm{m}^{-3}$ $\mathrm{d}^{-1}$. At the start, the reactors were inoculated with methanogenic ecosystems either adapted to TOC contamination for a long time, or confronted for the first time to TOC (non-adapted ecosystem). In addition, ozonation was combined to the anaerobic reactor as a post-treatment in order to assess the efficiency of such a combination. The digested sludge was ozonized in a 1-L fed batch reactor as detailed in Bernal-Martínez et al. (2005). Biogas composition and flow measurement were estimated according to Trably et al. (2003).

Alternatively, the aerobic reactors were operated with a hydraulic retention time of $20 \mathrm{~d}$ and a maximum daily organic load of $1.2 \mathrm{~kg}$ COD m $\mathrm{m}^{-3} \mathrm{~d}^{-1}$. They were fed with the same long-term TOC-contaminated sewage sludge. The air flow rate was $0.3 \mathrm{~L} \mathrm{~L}^{-1} \mathrm{~min}^{-1}$. Aerobic reactors were operated according to Trably and Patureau (2006).

\section{Biological reactors fed with TOC-spiked sewage sludge}

In order to assess the impact of various types of sludge on the fate of TOCs under anaerobic conditions, similar anaerobic digesters were operated as described above, except that they were fed with primary, secondary, and thermally pretreated $\left(165^{\circ} \mathrm{C}, 30 \mathrm{~min}\right)$ sludge spiked with nonylphenol at $100 \mu \mathrm{g} \mathrm{g} \mathrm{g}^{-1} \mathrm{DM}$, each $\mathrm{PCB}$ at $5 \mu \mathrm{g} \mathrm{g}^{-1} \mathrm{DM}$, and each $\mathrm{PAH}$ at $5 \mu \mathrm{g}$ $\mathrm{g}^{-1}$ DM except for indeno(1,2,3-cd)pyrene at $1 \mu \mathrm{g} \mathrm{g}^{-1}$ DM (Barret et al., 2010a). Thus, the TOC loads on the digesters were similar for various types of sludge. Centrifugation of sludge $\left(12000 \times g, 20 \mathrm{~min}, 35^{\circ} \mathrm{C}\right)$ followed by filtration at $1.2 \mathrm{~mm}(\mathrm{GF} / \mathrm{C}$ filter, Whatman) were carried out to separate the particles from the supernatant containing the dissolved and colloidal matter (DCM). TS and VS of the total sludge and the DCM fraction were measured by weighing the samples after heating at $105{ }^{\circ} \mathrm{C}$ for $24 \mathrm{~h}$ and further heating at $550{ }^{\circ} \mathrm{C}$ overnight. Chemical oxygen demand, proteins, carbohydrates, volatile fatty acids, mineral density, low-molecular-weight DCM fraction $(<1 \mathrm{kDa})$, and organic carbon in particles and in DCM were determined in the inlet and outlet of the reactors at a steady state according to Barret et al. (2010b).

\section{TOC enrichment cultures}

In order to identify and characterise the anaerobic microbial population implied in TOC degradation, enrichment cultures on PAEs and nonylphenol at high concentrations (between 10 and $500 \mathrm{mg} \mathrm{L}^{-1}$ ) were carried out in $250-\mathrm{mL}$ serum bottles. These enriched anaerobic continuous reactors, operated at $37{ }^{\circ} \mathrm{C}$ with a hydraulic retention time of $20 \mathrm{~d}$, were inoculated with an anaerobic digested sludge and fed with a synthetic medium supplemented with PAEs or nonylphenol. The microbial communities were analysed by DNA fingerprints and sequences according to Trably et al. (2005, 2008).

\section{Assessment of TOC sorption equilibrium in sludge}

TOC partition coefficients in sludge $\left(K_{\mathrm{d}}\right)$ were determined in the various types of sludge by varying the DCM concentration. Variations of DCM concentrations were obtained by diluting each sludge with its own supernatant previously separated (centrifugation and filtration at $1.2 \mathrm{~mm}$ ), and with water in different proportions. Dependence of $K_{\mathrm{d}}$ on DCM concentration was measured for each sludge and each TOC. A non-linear regression Levenberg-Marquardt algorithm (Marquardt, 1963) was used to minimise the sum of square errors and to estimate $K_{\text {part }}$ and $K_{\mathrm{DCM}}$, the equilibrium constants of sorption to particles and DCM, respectively, as shown in Barret et al. (2010b, c).

\section{TOC analysis}

In order to determine the total TOC concentration, sludge samples were dried and sieved. The PAHs (fluorene, phenanthrene, anthracene, fluoranthene, pyrene, benzo(a)anthracene, chrysene, benzo(b)fluoranthene, benzo(k)fluoranthene, benzo(a)pyrene, dibenzo(a,h)anthracene, benzo(g,h,i)perylene, indeno(1,2, 3-cd)pyrene), NPEs (nonylphenol, nonylphenol-monoethoxylate, and nonylphenol-di-ethoxylate) and PCBs (28, 52, 101, 118, 138, 153, and 180) were solventextracted from $0.5 \mathrm{~g}$ of dry sludge samples using the ASE-200 system (Dionex ${ }^{\text {TM}}$-Moduleware V. 3.01 Bios 30.0, Dionex Corporation, USA) as described previously by Trably et al. (2004) and Hernandez-Raquet et al. (2007). PAHs and NPEs were analysed using high performance liquid chromatography coupled to fluorescence detection according to the respective methods previously described (Trably et al., 2004; Patureau et al., 2007). The PCBs were quantified by gas chromatography coupled to an electron capture detector equipped with a capillary column, according to $\mathrm{Pa}$ - 
tureau and Trably (2006). The PAEs were determined as described in Trably et al. (2008), briefly consisting of liquid-liquid extraction and gas chromatography-mass spectrometry (GC-MS) analysis.

\section{Statistical analysis}

TOC removals were compared using a Student's $t$ test. For all tests, $P=0.05$ was used to denote statistical significance..

\section{RESULTS AND DISCUSSION}

TOC dynamic during sewage sludge anaerobic digestion

In this study, several biological reactors were fed with long-term TOC-contaminated sewage sludge. Indeed, according to Eggen and Majcherczyk (1998), the addition of contaminants could modify their removal assessment because of the modification of the interactions occurring between contaminants and organic matter. TOC abiotic losses were also estimated with chemically sterilized reactors using sodium azide $\left(100 \mathrm{mmol} \mathrm{L}^{-1}\right)$ under the same conditions.

Under mesophilic methanogenic conditions (35 ${ }^{\circ} \mathrm{C}$ ), we clearly observed significant removal of $13 \mathrm{PAHs}$ (Trably et al., 2003), 7 PCBs (Patureau and Trably, 2006), and NPEs (Patureau et al., 2008) with average removals of $46 \% \pm 4 \%, 40 \% \pm 5 \%$, and $25 \% \pm 6 \%$, respectively. $\mathrm{PAH}$ and $\mathrm{PCB}$ abiotic losses were strictly limited to the lightest compounds such as fluorene, phenanthrene, anthracene, PCB 52, PCB 101, and PCB 118, and remained below 20\%. NPE abiotic losses were limited to very low amounts, around $4 \% \pm 7 \%$. Fig. 1 illustrated the abiotic losses and biological anaerobic removals of 13 PAHs.

Different removals were observed according to the molecular weight and the type of molecule: the lightest PAHs were better degraded than heavier ones. In contrast, the highly chlorinated PCBs were degraded faster. These results are consistent with the published literature (Chang et al., 1999, 2005), even with data obtained under highly simplified and acclimated/enriched batch systems, synthetically spiked with the targeted compounds, and not offering a comparison with abiotic conditions. For example, biodegradation of the lightest PAHs was reported under sulfatereducing conditions in the case of highly contaminated sediment (Rockne and Strand, 1998) and under methanogenic conditions with an enriched adapted culture coming from a long-term highly polluted sediment (Chang et al., 2002). Our work was thus the first to

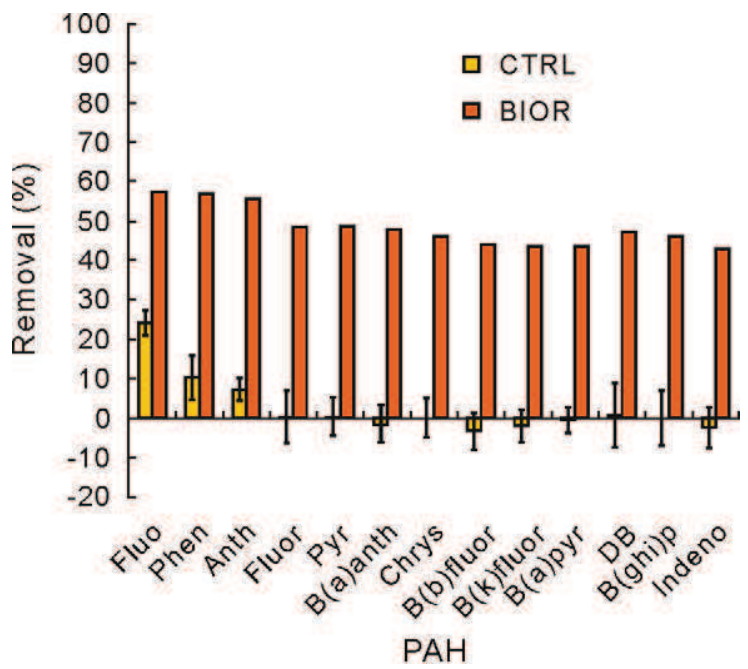

Fig. 1 Removal of polycyclic aromatic hydrocarbons (PAH) including fluorene (Fluo), phenanthrene (Phen), anthracene (Anth), fluoranthene (Fluor), pyrene (Pyr), benzo(a)anthracene (B(a)anth), chrysene (Chrys), benzo(b)fluoranthene (B(b)fluor), benzo(k)fluoranthene (B(k)fluor), benzo(a)pyrene (B(a)pyr), dibenzo(a,h)anthracene (DB), benzo(g,h,i)perylene (B(ghi)p), and indeno(1,2,3-cd)pyrene) (Indeno) in abiotic reactors (CTRL) and biological reactors (BIOR) under anaerobic mesophilic conditions $\left(35^{\circ} \mathrm{C}\right)$ in 5 - $\mathrm{L}$ continuous stirred tank reactors with a hydraulic retention time of $40 \mathrm{~d}$.

fully simulate the real environment found in anaerobic treatment systems.

In this study with the low contaminated sludge, all TOC removals were closely related to TS removals. This meant that TOC transfer and diffusion are involved in such a process and that bioavailability remained an important limiting factor. In order to enhance the mass transfer and thus TOC removals, we tested various operating conditions such as an increase of temperature and the addition of surfactant or methanol (Trably, 2002). In the case of PAHs, removals were enhanced under thermophilic conditions $\left(55^{\circ} \mathrm{C}\right)$. For the lightest PAHs, the removal enhancement was due to a significant increase in abiotic losses. However, for the heaviest PAHs, it was concluded that the increase of removal performances was due to an increase in $\mathrm{PAH}$ diffusion from solids to a more extractable compartment (Trably et al., 2003).

We also compared anaerobic versus aerobic conditions. This latter condition was always better in terms of TOC removal: at $45{ }^{\circ} \mathrm{C}$, around $80 \%$ of PAH removal was observed with $41 \%$ of total solid reduction (Trably and Patureau, 2006). Similar results were observed for NPE removal with the highest efficiency for the aerobic mesophilic (Hernandez-Raquet et al., 2007) and thermophilic (Patureau et al., 2008) processes.

At the same time, a combination of anaerobic process and chemical process such as ozonation was also 
tested in order to increase TOC removal. This combination increased NPE (Patureau et al., 2008) and PAH (Bernal-Martinez et al., 2005) removals by almost a factor of 2 with regard to the performances observed in the one-step anaerobic reactors. By using a partial least square regression, PAH removal by ozonation was found to be correlated to PAH solubility and the number of 5-carbon rings (Carrère et al., 2006). The presence of soluble organic matter in the sludge was also a limiting factor for ozone attack on PAHs.

The results previously presented emphasized on one hand the potential of technological solutions for reducing the contents of such refractory TOCs in sewage sludge, and, on the other hand, the probable existence of anaerobic microorganisms able to degrade such TOCs. However, to this point, the anaerobic digestion processes were only studied empirically, following a black box approach. To go further and improve our understanding on the driving mechanisms, we developed a mechanistic and conceptual approach in which a complex network of interactions between the three actors of the system, i.e., TOC, microorganisms, and matrix, must be considered (Fig. 2). The structure of the microbial consortium, with respect to each TOC, defines a microbial potential throughout the presence and abundance of the active microorganisms. In addition, the interactions between the microbial ecosystem and the matrix define the basal metabolism of the system, which can influence the biodegradation of TOCs throughout cometabolism processes. Finally, the physico-chemical interactions between TOC and matrix, in terms of sorption, are likely to determine the bioavailability of TOCs towards the microorganisms, and consequently the biodegradation activity. Several

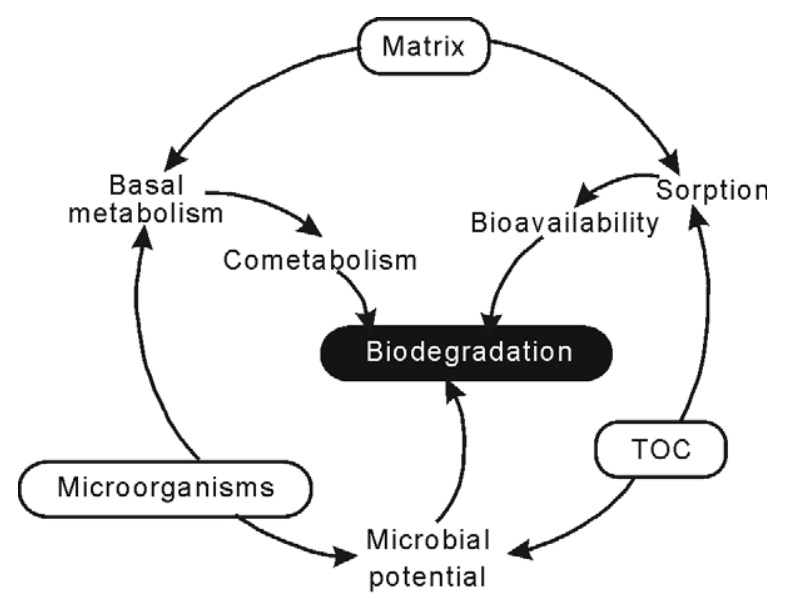

Fig. 2 Network of interactions between the three factors (trace organic contaminant (TOC), matrix, and microorganisms) influencing the biodegradation of TOCs during anaerobic digestion of contaminated sludge. approaches were developed in order to evidence, understand, and model each link of this conceptual network, either individually or following an integrated way of investigation.

\section{Microbial processes involved in TOC removal}

Over the past ten years, various experiments were conducted for better understanding the microbial processes involved in TOC removal. More particularly, the role of specific microbial populations was investigated in anaerobic mixed cultures removing biologically various TOCs sorbed onto sewage sludge. With regard to a non-adapted anaerobic ecosystem sampled from a mesophilic digester treating uncontaminated sewage sludge, PAH removal was observed only when the microbial ecosystem had been adapted for several years to a low but persistent level of contamination (Trably et al., 2003). In fact, the adapted ecosystem corresponded to the outlet of an industrial anaerobic digester treating sewage sludge persistently contaminated by PAHs concentrated at an order of magnitude of few mg per $\mathrm{kg}$ of dry matter. PAH removal performances were compared between the adapted and non-adapted ecosystems. Lower removals were observed with the nonadapted ecosystem (ranging from $5 \%$ to $25 \%$ according to PAH molecular weights) than the adapted ecosystem (ranging from $40 \%$ to $60 \%$ ). Moreover, the heavier the PAH, the higher the difference. This result evidenced the importance of a long period of contamination for adapting the microbial ecosystem. These performances were significantly enhanced by bioaugmention of the inoculum. In fact, when using as initial inoculum a sludge mixture composed of $10 \%$ and $90 \%$ of adapted and non-adapted microbial consortia, respectively, similar removal performances were observed for the lightest PAHs, but slightly lower removal performances for the heavier ones (Trably et al., 2003). It was concluded that a long term adaptation of the methanogenic microbial ecosystem was required for efficiently removing PAHs and more specifically the heavier ones. In addition, the rates of PAH removal for both the non-adapted and bioaugmented reactors were significantly lower than the TS reduction rates. Therefore, PAH removal in the adapted reactor was mainly due to an effective biological activity and did not only result from an abiotic phenomenon of physical transfer, i.e., non-specific PAH incorporation into the non-extractable fraction of the solid particles. In this context, the archaeal population from the adapted ecosystem was characterized and several members of the methanogenic genera were identified. It was shown 
that methanogenic activity was essential for effective PAH removal, likely due to the thermodynamic limitations of the anaerobic pathways (Trably, 2002). Moreover, a specific pattern of the microbial population was observed, suggesting that the adaptation of the ecosystem implied the presence of adapted archaeal methanogens as well as adapted bacterial species. To better understand the microbial processes involved in such anaerobic degradation pathways, ${ }^{14} \mathrm{C}$ benzo(a)pyrene was used. Although a significant part (about $10 \%$ ) of the molecules were incorporated into the non-extractable fraction of the solids, it was definitely concluded that PAH biodegradation occurred under anaerobic conditions and corresponded to approximately $40 \%$ of $\mathrm{PAH}$ removal for all compounds (data not shown).

In order to identify specifically the microorganisms potentially involved in TOC removal, enrichment procedures were performed from adapted ecosystems in continuous stirred tank reactors fed with a synthetic medium supplemented with each contaminant (dibutyl phthalate (DBP) or nonylphenol). This procedure rapidly selected simplified microbial populations with a high capacity of degradation. During the enrichment, the TOC removal was higher than $90 \%$ and the microbial population was characterized. The dominant bacterial species in the DBP-degrading culture was affiliated to Soehngenia saccharolytica, a microorganism described previously as an anaerobic benzaldehyde degrader (Trably et al., 2008). Within the archaeal community, there was a shift between two different species of the genus Methanosaeta, indicating a highly specific impact of DBP or degradation products on archaeal species. This was consistent with previous results, suggesting that the populations of archaeal methanogens were very specific to TOC either because the presence of TOC caused less inhibition of these populations or, more likely, because methanogens favoured the local conditions through specific syntrophic relationships with bacterial degraders. To better understand the spatial relationships between microorganisms, DNA probes targeting mRNA were designed from molecular fingerprint characterization of the enriched populations. Spatial repartition of the dominant microorganisms was observed by fluorescent in-situ hybridization and showed that they were mainly present in well structured flocs, suggesting the occurrence of physiological as well as energetic interactions/synergies between archaeal and bacterial populations.

Similar results were observed in nonylphenoldegrading enrichment cultures. The dominant bacterial species were affiliated to the genera Pseudomonas and Alcaligenes, previously described as $p$-cresol and phenol degraders, respectively. This suggested that phenol may be a probable by-product of nonylphenol degradation pathway. From these enrichments, several microorganisms were isolated and physiologically and phylogenetically characterised. Some of them were interesting because hybridization revealed the presence of bacterial/archaeal consortia which were so closely associated that they were impossible to dissociate, suggesting that tight interactions occurred. Hypothesis of cometabolism: experimental evidence
and modelling

Although certain TOCs such as low-molecularweight PAHs and nonylphenol can be used as sole carbon sources by methanogenic consortia (Trably et al., 2005b; Chang et al., 2006, 2008), it has not been shown for high-molecular-weight PAHs. In the case of highly recalcitrant TOCs for which biodegradation is not thermodynamically favoured, the metabolic activity that leads to their removal is possible when combined to other metabolic routes. Indeed, the metabolism of co-substrates can generate carbon and energy fluxes in the cells. This physiological state might stimulate the metabolic pathway of TOC degradation. One experimental evidence for this interaction is the increase of TOC biodegradation when a readily biodegradable substrate such as acetate, yeast extract or cellulose is added (Chang et al., 2004; Dionisi et al., 2006). However, in some cases, no effect was reported (Bertin et al., 2007). This discrepancy in the literature might emphasize the need for an integrated approach to study the implication of cometabolism in the fate of TOCs during the anaerobic digestion of contaminated sludge. Indeed, adding a readily biodegradable substrate into sludge may modify not only the basal metabolism of the methanogenic consortium and thereby the cometabolism, but it is also likely to influence the microbiological potential since the structure of the ecosystem established in the process depends on the characteristics of the feed. In addition, the bioavailability of the pollutants towards the active microorganisms may change when the matrix composition and thus its sorption ability is modified. No study which took all these mechanisms into account had been performed when we published a paper in which an integrated approach was developed (Barret et al., 2010a). This research demonstrated that indeed, cometabolism was one of the driving mechanisms. It was also shown that other mechanisms did concomitantly influence the biodegradation of TOCs and had to be included in the modelling of pollutant fate. 
In addition, Delgadillo-Mirquez et al. (2011) compared the metabolism with the cometabolism for PAH degradation modelling during anaerobic digestion of contaminated sludge. In this study, metabolism was modelled on the basis of Monod-type kinetics with specific PAH-degraders and cometabolism kinetics was adapted from the Criddle (1993) equation that considers cometabolism and bioavailability. This modified equation enhances the cometabolic degradation with generation of reductants from biodegradation of a growth substrate and in its absence, the TOC transformation is linked to endogenous decay. PAH degradation with a specific microorganism resulted in an overestimation of experimental data while the cometabolism model closely followed the dynamic evolution of the PAH compounds (Fig. 3). The results suggested that a cometabolism pathway could be the main mechanism for hydrophobic pollutant removal. An ecological explanation of cometabolism is that the removal of compounds present only in trace levels $\left(\mathrm{ng} \mathrm{L}^{-1}\right.$ or $\mu \mathrm{g}$ $\mathrm{L}^{-1}$ ) does not result in any significant biomass growth (Clara et al., 2005). Indeed, such a mechanism was defined (Horvath, 1972) as the ability of the organism to attack a pollutant without a necessary assimilation of the metabolic by-products generated from its oxidation.

Physico-chemical processes involved in TOC removal: towards the bioavailability concept

Bioavailability, defined as the concentration available for degradation by the microorganisms, is usually assumed to govern the biodegradation of hydrophobic
TOCs in sludge (Chang et al., 2003; Patureau and Trably, 2006). Several assumptions can be found in the literature concerning the bioavailable fraction of contaminants. The most widespread one considers that the aqueous contaminants are bioavailable (ArtolaGaricano et al., 2003; Urase and Kikuta, 2005). However, the aqueous fraction includes not only free TOCs but also TOCs sorbed to dissolved and colloidal matter (DCM). Indeed, the DCM compartment of sludge is defined as the centrifugation supernatant (12000 g, $20 \mathrm{~min}, 35^{\circ} \mathrm{C}$ ) filtered at $1.2 \mathrm{~mm}$ (Barret et al., 2010c). The two sludge compartments have not usually been differentiated in the literature even though the existing interactions between TOCs and DCM are likely to modulate their bioavailability (Perminova et al., 2001; Smith et al., 2009). Further research was thus needed to clearly establish the link between bioavailability and sorption phenomena and demonstrate whether bioavailability is really one of the mechanisms which drive the fate of TOCs.

A new procedure was developed to assess the equilibrium constants of sorption in sludge which is considered as a three-compartment matrix where TOCs coexist in three states (Fig. 4): freely dissolved, sorbed to DCM, and sorbed to particles (Barret et al., 2010c). This methodology was applied to a wide range of TOCs and sludge samples (Barret et al., 2010b). The data obtained were used to build a model in which equilibrium constants were expressed as a function of compounds and sludge characteristics (Barret et al., 2010b).

This work made it possible to classify the influence
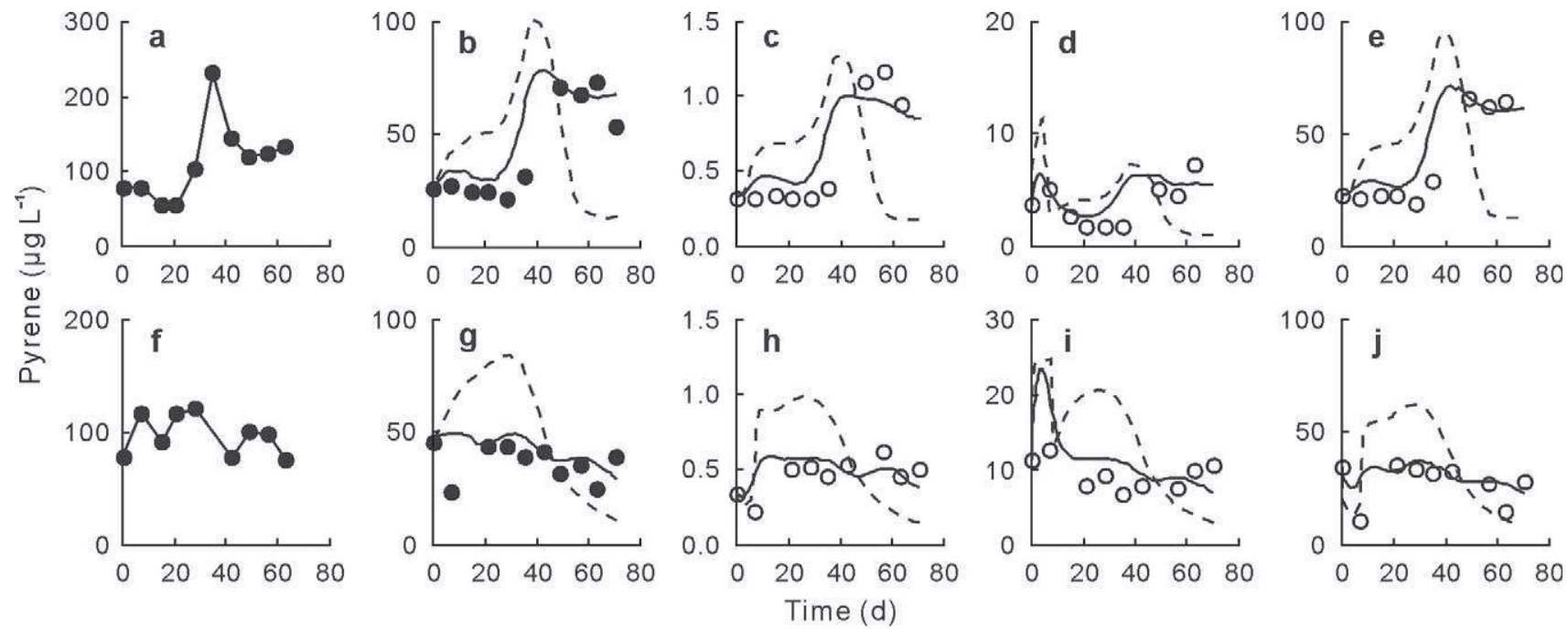

Fig. 3 Pyrene behaviour in primary ( $\mathrm{a}-\mathrm{e})$ and secondary $(\mathrm{f}-\mathrm{j}$ ) sludge reactors: influent concentration of pyrene (a and $\mathrm{f}$ ), effluent concentration of pyrene ( $\mathrm{b}$ and $\mathrm{g}$ ), freely dissolved pyrene ( $\mathrm{c}$ and $\mathrm{h}$ ), pyrene sorbed to dissolved and colloidal matter ( $\mathrm{d}$ and i), and pyrene sorbed to particles (e and j). Grey line: influent concentration; black circle: experimental data; white circle: values estimated from two equilibrium constants; black line: model with cometabolism; dashed line: model with Monod-type metabolism (considering the aqueous phase as the bioavailable compartment). 


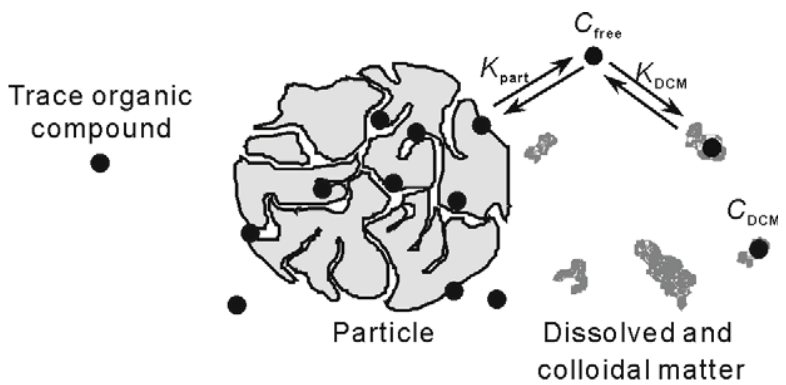

Fig. 4 Representation of the three-compartment model of a trace organic contaminant (TOC) in sludge (Barret et al., 2010c). $C_{\text {free }}\left(\mathrm{mg} \mathrm{mL} \mathrm{mL}^{-1}\right)$ : concentration of freely dissolved TOC; $C_{\mathrm{DCM}}\left(\mathrm{mg} \mathrm{g}^{-1}\right)$ : concentration of TOC sorbed to dissolved and colloidal matter (DCM); $C_{\text {part }}\left(\mathrm{mg} \mathrm{g}^{-1}\right)$ : concentration of TOC sorbed to particles; $K_{\text {part }}$ : the equilibrium constant of TOC sorption to particles $\left(\mathrm{mL} \mathrm{g}^{-1}\right) ; K_{\mathrm{DCM}}$ : the equilibrium constant of sorption to DCM $\left(\mathrm{mL} \mathrm{g}^{-1}\right)$.

ences of the TOC properties and the sludge characteristics on TOC sorption. One meaningful result was that the physical and chemical properties of sludge had a higher influence than TOC characteristics, contrary to what is commonly admitted in other environmental matrices such as soil and sediments (Karickhoff et al., 1979). One other outcome of this study was the use of the model as a predictive tool. This option was exploited to assess the distribution of TOCs within the three compartments in anaerobic continuous bioreactors, and link these data to the microbial activity of biodegradation (Barret et al., 2010a). Hence, the widespread assumption that aqueous contaminants are bioavailable was experimentally validated. Evidence was also provided for the link between bioavailabilty and biodegradation, and a formalism was proposed to model the combined effects of bioavailability and cometabolism:

$\frac{r_{\mathrm{TOC}}}{C_{\mathrm{TOC}, \mathrm{aqu}}}=\frac{T_{\mathrm{TOC}, \mathrm{TS}}}{K_{\mathrm{TOC}}}\left(r_{\mathrm{TS}}-r_{0}\right)$

where $r_{\text {TOC }}$ is the removal rate of a TOC $\left(\mu \mathrm{g} \mathrm{L}^{-1}\right.$ $\left.\mathrm{d}^{-1}\right) ; C_{\text {TOC, aqu }}$ is the volumetric concentration of the TOC in the aqueous phase, including freely dissolved and sorbed-to-DCM compounds $\left(\mu \mathrm{g} \mathrm{L}{ }^{-1}\right) ; T_{\mathrm{TOC}, \mathrm{TS}}$ is the TOC transformation capacity with TS as the cometabolic substrate $\left(\mu \mathrm{g} \mathrm{g}^{-1} \mathrm{TS}\right) ; K_{\text {TOC }}$ is the halfsaturation constant of the TOC in the Monod-type formalism $\left(\mu \mathrm{g} \mathrm{L}{ }^{-1}\right) ; r_{\mathrm{TS}}$ is the removal rate of $\mathrm{TS}\left(\mathrm{g} \mathrm{L}^{-1}\right.$ $\left.\mathrm{d}^{-1}\right)$; and $r_{0}$ is the threshold value for the removal rate of $\mathrm{TS}\left(\mathrm{g} \mathrm{L}^{-1} \mathrm{~d}^{-1}\right)$. Using this equation and considering the various distributions of pollutants in the sludge compartments, Delgadillo-Mirquez et al. (2011) developed a model for the behaviour of PAHs in anaerobic reactors. This model allowed to test various hypotheses, like determining which compartment is the bioavailable one. To this purpose, bioavailability of hydrophobic TOCs was evaluated in the freely dissolved fraction, aqueous fraction (including freely dissolved and sorbed-to-DCM compounds), and all fractions (aqueous fraction and sorbed-to-particles fraction) as proposed by Fountoulakis et al. (2006). Simulation results (Delgadillo-Mirquez et al., 2011) confirmed that the aqueous fraction was the main bioavailable compartment. Considering this, the cometabolism kinetic parameters were lower than those of substrate metabolism supporting the microbial growth (Chang et al., 1993; Alvarez-Cohen and Speitel, 2001; Haws et al., 2006).

\section{CONCLUSIONS}

The results of this study showed the anaerobic potential of low contaminated environments to remove TOCs. It was also highlighted that technological solutions can be applied to enhance this potential, by enhancing the temperature or combining biological and physico-chemical processes. Such enhancement strategies can be empirically elaborated by modifying the operational parameters or, more thinkable, by deeply understanding the mechanisms driving the fate of the TOCs. Our proposed conceptual and mechanistic approach considering the network of interactions between the matrix, the TOCs, and the microorganisms helped us to better understand which compartment was bioavailable and underlined the importance of considering cometabolism when studying the biodegradation of such contaminants. Moreover, this approach, developed on anaerobic processes, can be transposed to other types of matrices such as activated sludge, sediments, and soils. The main idea was to observe the repartition of the TOCs in organic matter that could be separated by particle size or biochemical affinity or a combination of both. It could be particularly relevant to adopt such an approach in the context of sewage sludge which is usually spread onto agricultural soils after stabilization by anaerobic digestion or composting. The nature, the level, and the sorption behaviour of the pollutants in the stabilized sludge and, as a result, the risks associated with their use on agricultural soils would depend on the raw materials, their final load, and their evolution over time. Each sludge stabilization process thus induced a particular dissipation of the TOCs, including their transformation and/or their association to various matter compartments of the considered matrix; this dissipation process likely interacted with the TOC fate after sludge spreading. It is thus important to improve the overview of sludge quality in terms of the content and fraction localisation 
(speciation) of TOCs and to link their fate in processes to their fate in soil.

\section{ACKNOWLEDGEMENT}

We would like to thank the French, Mexican, and Chilean governments, the Ibague University, Colombia, and the Administrative Department of Science, Technology and Innovation (COLCIENCIAS), Colombia, for Ph.D. student grants.

\section{REFERENCES}

Artola-Garicano, E., Borkent, I., Damen, K., Jager, T. and Vaes, W. H. J. 2003. Sorption kinetics and microbial biodegradation activity of hydrophobic chemicals in sewage sludge: Model and measurements based on free concentrations. Environ. Sci. Technol. 37: 116-122.

Alvarez-Cohen, L. and Speitel, G. E. Jr. 2001. Kinetics of aerobic cometabolism of chlorinated solvents. Biodegradation. 12: 105-126.

Barret, M., Carrère, H., Delgadillo, L. and Patureau, D. 2010a. $\mathrm{PAH}$ fate during the anaerobic digestion of contaminated sludge: Do bioavailability and/or cometabolism limit their biodegradation? Water Res. 44: 3797-3806.

Barret, M., Carrère, H., Latrille, E., Wisniewski, C. and Patureau, D. 2010b. Micropollutant and sludge charaterization for modeling sorption equilibria. Environ. Sci. Technol. 44: 1100-1106.

Barret, M., Patureau, D., Latrille, E. and Carrère, H. 2010c. A three-compartment model for micropollutants sorption in sludge: methodological approach and insights. Water Res. 44: 616-624.

Bernal-Martinez, A., Carrère, H., Patureau, D. and Delgenès, J. P. 2005. Combining anaerobic digestion and ozonation to remove PAH from urban sludge. Process Biochem. 40: 3244-3250.

Bertin, L., Capodicasa, S., Occulti, F., Girotti, S., Marchetti, L. and Fava, F. 2007. Microbial processes associated to the decontamination and detoxification of a polluted activated sludge during its anaerobic stabilization. Water Res. 41: 2407-2416.

Bolz, U., Hagenmaier, H. and Körner, W. 2001. Phenolic xenoestrogens in surface water, sediments, and sewage sludge from Baden-Württemberg, south-west Germany. Environ. Pollut. 115: 291-301.

Carrère, H., Bernal-Martinez, A., Patureau, D. and Delgenès, J. P. 2006. Parameters explaining removal of PAHs from sewage sludge by ozonation. AIChE J. 52: 3612-3620.

Celiz, M. D., Pérez, S., Barceló, D. and Aga, D. S. 2009. Trace analysis of polar pharmaceuticals in wastewater by LC-MS-MS: Comparison of membrane bioreactor and activated sludge systems. J. Chromatogr. Sci. 47: 19-25.

Chang, B. V., Chang, I. T. and Yuan, S. Y. 2008. Anaerobic degradation of phenanthrene and pyrene in mangrove sediment. Bull. Environ. Contam. Toxicol. 80: 145-149.

Chang, B. V., Chang, S. W. and Yuan, S. Y. 2003. Anaerobic degradation of polycyclic aromatic hydrocarbons in sludge. Adv. Environ. Res. 7: 623-628.

Chang, B. V., Chiang, F. and Yuan, S. Y. 2005. Biodegradation of nonylphenol in sewage sludge. Chemosphere. 60: $1652-1659$.
Chang, B. V., Chou, S. W. and Yuan, S. Y. 1999. Microbial dechlorination of polychlorinated biphenyls in anaerobic sewage sludge. Chemosphere. 39: 45-54.

Chang, B. V., Shiung, L. C. and Yuan, S. Y. 2002. Anaerobic biodegradation of polycyclic aromatic hydrocarbon in soil. Chemosphere. 48: 717-724.

Chang, B. V., Yu, C. H. and Yuan, S. Y. 2004. Degradation of nonylphenol by anaerobic microorganisms from river sediment. Chemosphere. 55: 493-500.

Chang, M. K., Voice, T. C. and Criddle, C. S. 1993. Kinetics of competitive inhibition and cometabolism in the biodegradation of benzene, toluene, and $p$-xylene by two Pseudomonas isolates. Biotechnol. Bioeng. 41: 1057-1065.

Chang, W., Um, Y. and Holoman, T. R. P. 2006. Polycyclic aromatic hydrocarbon (PAH) degradation coupled to methanogenesis. Biotechnol. Lett. 28: 425-430.

Clara, M., Kreuzinger, N., Strenn, B., Gans, O. and Kroiss, H. 2005. The solids retention time - a suitable design parameter to evaluate the capacity of wastewater treatment plants to remove micropollutants. Water Res. 39: 97-106.

Criddle, C. S. 1993. The kinetics of cometabolism. Biotechnol. Bioeng. 41: 1048-1056.

Dardre, P. D. 1998. Environmental contaminants in milk: the problem of organochlorine xenobiotics. Biochem. Soc. Trans. 26: 106-112.

Delgadillo-Mirquez, L., Lardon, L., Steyer, J. P. and Patureau, D. 2011. A new dynamic model for bioavailability and cometabolism of micropollutant during anaerobic digestion. Water Res. 45: 4511-4521.

Desbrow, C., Routledge, E. J., Brighty, G. C., Sumpter, J. P. and Waldock, M. 1998. Identification of estrogenic chemicals in STW effluent. 1. Chemical fractionation and in vitro biological screening. Environ. Sci. Technol. 32: 1549-1558.

Dionisi, D., Bertin, L., Bornoroni, L., Capodicasa, S., Papini, M. P. and Fava, F. 2006. Removal of organic xenobiotics in activated sludges under aerobic conditions and anaerobic digestion of the adsorbed species. J. Chem. Technol. Biotechnol. 81: 1496-1505.

Eggen, T. and Majcherczyk, A. 1998. Removal of polycyclic aromatic hydrocarbons (PAH) in contaminated soil by white rot fungus Pleurotus ostreatus. Int. Biodeter. Biodegr. 41: $111-117$.

Fauser, P., Vikelsøe, J., Sørensen, P. B. and Carlsen, L. 2003. Phthalates, nonylphenols and LAS in an alternately operated wastewater treatment plant-fate modelling based on measured concentrations in wastewater and sludge. Water Res. 37: 1288-1295.

Fountoulakis, M. S., Stamatelatou, K., Batstone, D. J. and Lyberatos, G. 2006. Simulation of DEHP biodegradation and sorption during the anaerobic digestion of secondary sludge. Water Sci. Technol. 54: 119-128.

Gabet-Giraud, V., Miège, C., Choubert, J. M., Ruel, S. M. and Coquery, M. 2010. Occurrence and removal of estrogens and beta blockers by various processes in wastewater treatment plants. Sci. Total. Environ. 408: 4257-4269.

Gadd, G. M. 2009. Biosorption: critical review of scientific rationale, environmental importance and significance for pollution treatment. J. Chem. Technol. Biotechnol. 84: 13-28.

Gibson, J. and Harwood, C. S. 2002. Metabolic diversity in aromatic compound utilization by anaerobic microbes. Annu. Rev. Microbiol. 56: 345-369.

Haws, N. W., Ball, W. P. and Bouwer, E. J. 2006. Modeling and interpreting bioavailability of organic contaminant mixtures in subsurface environments. J. Contam. Hydrol. 82: 255292. 
Hernandez-Raquet, G., Soef, A., Delgenès, N. and Balaguer, P. 2007. Removal of the endocrine disrupter nonylphenol and its estrogenic activity in sludge treatment processes. Water Res. 41: 2643-2651.

Horvath, R. S. 1972. Microbial co-metabolism and the degradation of organic compounds in nature. Bacteriol. Rev. 36: 146-155.

Jensen, J. 1999. Fate and effects of linear alkylbenzene sulphonates (LAS) in the terrrestrial environment. Sci. Total. Environ. 226: 93-111.

Jobling, S. and Sumpter, J. P. 1993. Detergent components in sewage effluent are weakly estrogenic to fish: An in-vitro study using rainbow trout (Oncorhynchus mykiss) hepatocytes. Aquat. Toxicol. 27: 361-372.

Joss, A., Zabczynski, S., Göbel, A., Hoffmann, B., Löffler, D., McArdell, C. S., Ternes, T. A., Thomsen, A. and Siegrist, H. 2006. Biological degradation of pharmaceuticals in municipal wastewater treatment: Proposing a classification scheme. Water Res. 40: 1686-1696.

Karickhoff, S. W., Brown, D. S. and Scott, T. A. 1979. Sorption of hydrophobic pollutants on natural sediments. Water Res. 13: 241-248.

Mackay, D. and Fraser, A. 2000. Bioaccumulation of persistent organic chemicals: mechanisms and models. Environ. Pollut. 110: 375-391.

Magoarou, P. 2000. Urban waste water in Europe - what about sludge? In Langenkamp, H. and Marmo, L. (eds.) Proceedings of Workshop on Problems Around Sludge. EUR Vol. 19657. European Commission Joint Research Center, Brussels. pp. 9-16

Marquardt, D. 1963. An algorithm for least-squares estimation of nonlinear parameters. SIAM J. Appl. Math. 11: 431441.

Martin, O. V. and Voulvoulis, N. 2009. Sustainable risk management of emerging contaminants in municipal wastewaters. Philos. Trans. Roy. Soc. A. 367: 3895-3922.

Monteiro, S. C. and Boxall, A. B. A. 2010. Occurrence and fate of human pharmaceuticals in the environment. Rev. Environ. Contam. Toxicol. 202: 53-154.

Muller, M., Rabenoelina, F., Balaguer, P., Patureau, D., Lemenach, K., Budzinski, H., Barceló, D., De Alda, M. L., Kuster, M., Delgenès, J. P. and Hernandez-Raquet, G. 2008. Chemical and biological analysis of endocrine-disrupting hormones and estrogenic activity in an advanced sewage treatment plant. Environ. Toxicol. Chem. 27: 1649-1658.

Patureau, D. and Trably, E. 2006. Impact of anaerobic and aerobic processes on PolyChloroBiphenyl removal in contaminated sewage sludge. Biodegradation. 17: 9-17.

Patureau, D., Laforie, M., Lichtfouse, E., Caria, G., Denaix, L. and Schmidt, J. E. 2007. Fate of organic pollutants after sewage sludge spreading on agricultural soils: a 30 -years field-scale recording. Water Practice. Technol. 2: doi10. 2166/wpt.2007.008.

Patureau, D., Delgenes, N. and Delgenes, J. P. 2008. Impact of sewage sludge treatment processes on the removal of the en- docrine disrupters nonylphenol ethoxylates. Chemosphere. 72: $586-591$.

Perminova, I. V., Grechishcheva, N. Y., Kovalevskii, D. V., Kudryavtsev, A. V., Petrosyan, V. S. and Matorin, D. N. 2001. Quantification and prediction of the detoxifying properties of humic substances related to their chemical binding to polycyclic aromatic hydrocarbons. Environ. Sci. Technol. 35: 3841-3848.

Rockne, K. J. and Strand, S. E. 1998. Biodegradation of bicyclic and polycyclic aromatic hydrocarbons in anaerobic enrichments. Environ. Sci. Technol. 32: 3962-3967.

Servos, M. R. 1999. Review of the aquatic toxicity, estrogenic responses and bioaccumulation of alkylphenols and alkylphenol polyethoxylates. Water Qual. Res. J. Can. 34: 123177.

Smidt, H. and de Vos, W. M. 2004. Anaerobic microbial dehalogenation. Annu. Rev. Microbiol. 58: 43-73.

Smith, K. E. C., Thullner, M., Wick, L. Y. and Harms, H. 2009. Sorption to humic acids enhances polycyclic aromatic hydrocarbon biodegradation. Environ. Sci. Technol. 43: 7205-7211.

Trably, E. 2002. Study and optimization of the biodegradation of polycyclic aromatic hydrocarbons (PAHs) and polychlorobiphenyls (PCBs) during the anaerobic and aerobic digestion of long-term contaminated urban sludge. Ph.D. Thesis, University of Montpellier II, France.

Trably, E., Batstone, D. J., Christensen, N., Patureau, D. and Schmidt, J. E. 2008. Microbial dynamics in anaerobic enrichment cultures degrading di-n-butyl phthalic acid ester. FEMS Microbiol. Ecol. 66: 472-483.

Trably, E., Delgenès, N., Patureau, D. and Delgenès, J. P. 2004. Statistical tools for the optimization of a highly reproducible method for the analysis of polycyclic aromatic hydrocarbons in sludge samples. Int. J. Environ. Anal. Chem. 84: 9951008.

Trably, E., Lackner, S., Batstone, D. J., Patureau, D. and Schmidt, J. E. 2005. Identification of nonyl-phenol degraders in anaerobic enrichment of activated sludge mixture. In IWA (ed.) 4th IWA Activated Sludge Population Dynamics Specialist Conference on Microbial Population Dynamics in Biological Wastewater Treatment, 17-20 July, 2005, Brisbane, Gold Coast, Australia. pp. AS134

Trably, E. and Patureau, D. 2006. Successful treatment of low PAH-contaminated sewage sludge in aerobic bioreactors. Environ. Sci. Pollut. Res. 13: 170-176.

Trably, E., Patureau, D. and Delgenes, J. P. 2003. Enhancement of polycyclic aromatic hydrocarbons removal during anaerobic treatment of urban sludge. Water Sci. Technol. 48: 53-60.

Urase, T. and Kikuta, T. 2005. Separate estimation of adsorption and degradation of pharmaceutical substances and estrogens in the activated sludge process. Water Res. 39: 1289-1300.

Wild, S. R. and Jones, K. C. 1992. Polynuclear aromatic hydrocarbons uptake by carrots grown in sludge-amended soil. $J$. Environ. Qual. 21: 217-225. 